\title{
Integrated SEM, EDS, EBSD and EPMA Characterization of Aluminide Coatings on Stainless Steel
}

\author{
Bradley R. Johnson ${ }^{1 *}$, Nathan L. Canfield ${ }^{1}$, Bethany E. Matthews ${ }^{1}$ \\ 1.Pacific Northwest National Laboratory, Energy and Environment Directorate, Richland, WA, USA \\ * Corresponding author: Bradley.Johnson@pnnl.gov
}

The outer tube used to contain all of the components in a Tritium Producing Burnable Absorber Rod (TPBAR) is called the "cladding" and it is made out of 316 stainless steel. This tube serves a number of important functions such as protecting the TPBAR components from exposure to reactor coolant, and preventing the permeation of tritium from the inside of the TPBAR into the coolant. The cladding material itself, 316 stainless steel, is inherently corrosion resistant. Preventing tritium from permeating through the cladding is achieved by applying an aluminide barrier coating to the inside diameter of the stainless steel tubes [1]. The aluminide barrier coating is applied to the stainless steel cladding tube through a pack cementation coating process. This is a commonly used process for applying diffusional coatings to a variety of alloys including Ti, Ni-based super-alloys, and stainless steel [2]. For TPBAR coated cladding tubes, the aluminide barrier coating is applied in two steps First, a diffusional coating of aluminum is formed on the inside diameter of the stainless steel tube, and then subsequent deposition steps continue the transfer of aluminum from the pack to develop the full coating. Two heat treatment conditions are used during this process. First a 1 hour heat treatment is done in Ar atmosphere at $315.5^{\circ} \mathrm{C}$. For the second heat treatment, the atmosphere is switched to $\mathrm{H}_{2}$ and the temperature is increased to $718^{\circ} \mathrm{C}$ and held for 6.5 hours. The tubing is then furnace cooled to below $540^{\circ} \mathrm{C}$ in $\mathrm{Ar}$, then the Ar turned off and the furnace door is opened to rapid cool the part to safe handling temperature.

Advanced microstructural characterization of the cladding and the aluminide barrier coating interface is crucial to gain understanding about the deposition process how to modify it to optimize the quality of the coating. Characterization and comparison of pre- and post-irradiated coated cladding is being done to provide new insights into the impact of radiation exposure on the microstructure and its durability under extreme environments.

Samples were prepared for analysis by casting them in epoxy and polishing them using traditional metallurgical methods. Due to the desire to keep the coating intact and not de-laminate it from the tube, special care was used during the epoxy embedding process. Tube sections approximately $25 \mathrm{~mm}$ long were cast in epoxy, and a $6 \mathrm{~mm}$ piece was cut from the center of the tube (in order to avoid areas damaged at the rough cut tube ends) using a slow speed saw. The center section was then cut in half longitudinally to create two half-round circles. The two half circles were oriented with the curved faces perpendicular to the polishing face, and vacuum cast in epoxy to fill in any voids, to form the final mount.

An optimized polishing process was developed using SiC papers and progressing to woven polishing cloths with diamond suspensions at $9 \mu \mathrm{m}$, and $3 \mu \mathrm{m}$. Final polishing was accomplished using a vibratory polisher, a low-nap polishing pad, and non-aqueous colloidal $\mathrm{SiO}_{2}$. This approach was able to produce superior surface finishes that were adequate for collecting quality EBSD maps.

Specimens were primarily imaged in low vacuum mode, un-coated, using a BSE detector in order to examine the native, un-coated surface and take advantage of atomic number contrast mechanisms to 
emphasize slight variations in composition between the different phases (Figure 1A, B; Figure 2A). Specimens were coated with $20 \mathrm{~nm}$ of evaporated carbon to mitigate charging conditions with high current analytical needs required for EBSD, EDS, and EPMA. Analytical conditions for EDS and EBSD analysis were evaluated using various accelerating voltages, beam currents, detectors, vacuum levels and working distances to determine the optimum conditions. Example micrographs are shown in Figures 1 and 2.

The effect of the two-step deposition process on the coating microstructure was readily apparent by the abrupt change in microstructure of the coating. The microstructure was characterized as having four different regions; the interface with the substrate, the first layer with a columnar morphology, the transition between the two layers, and the outer layer, which had an equiaxed morphology.

References:

[1] G.W. Hollenberg, E.P. Simonen, G. Kalinin, A. Terlain, Fusion Engineering and Design 28 (1995), p. 190-208.

[2] R. Bianco, R.A. Rapp (1996) Pack cementation diffusion coatings. In: Stern K.H. (eds) Metallurgical and Ceramic Protective Coatings. (Springer, Dordrecht).
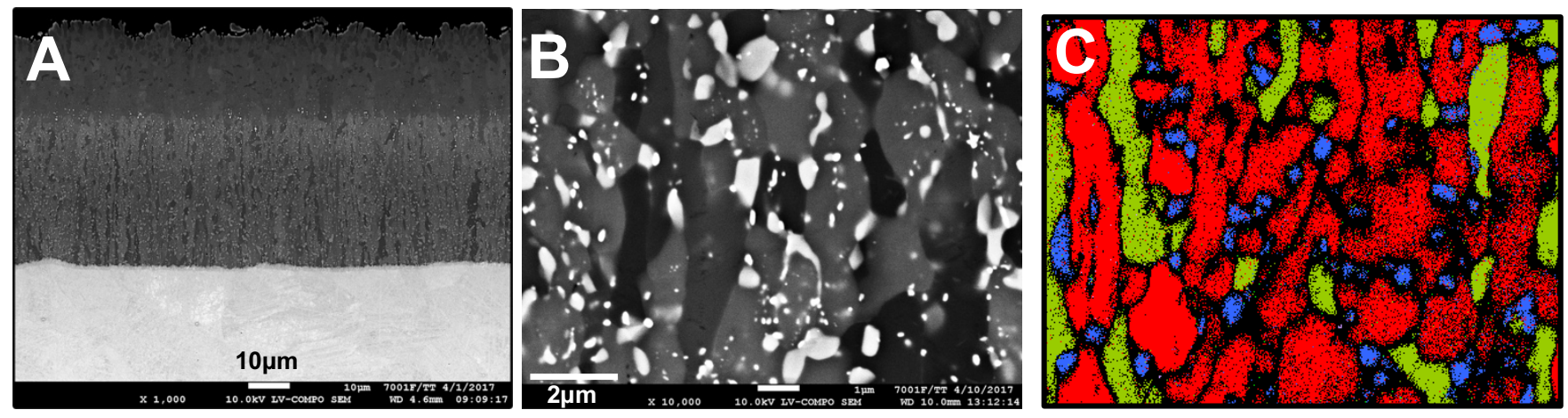

Figure 1. Micrographs of aluminide coating on 316 stainless steel. (A) BSE micrograph showing the full length of the coating; (B) Higher-magnification BSE micrograph showing the columnar structure of the first layer; (C) EBSD micrograph showing the presence of three different phases: $r e d=\mathrm{Fe}_{2.65} \mathrm{Ni}_{1.45} \mathrm{Al}_{9.9}$; green $=\mathrm{Al}_{5.6} \mathrm{Fe}_{2} ;$ blue $=\mathrm{Al}_{8} \mathrm{Cr}_{5}$
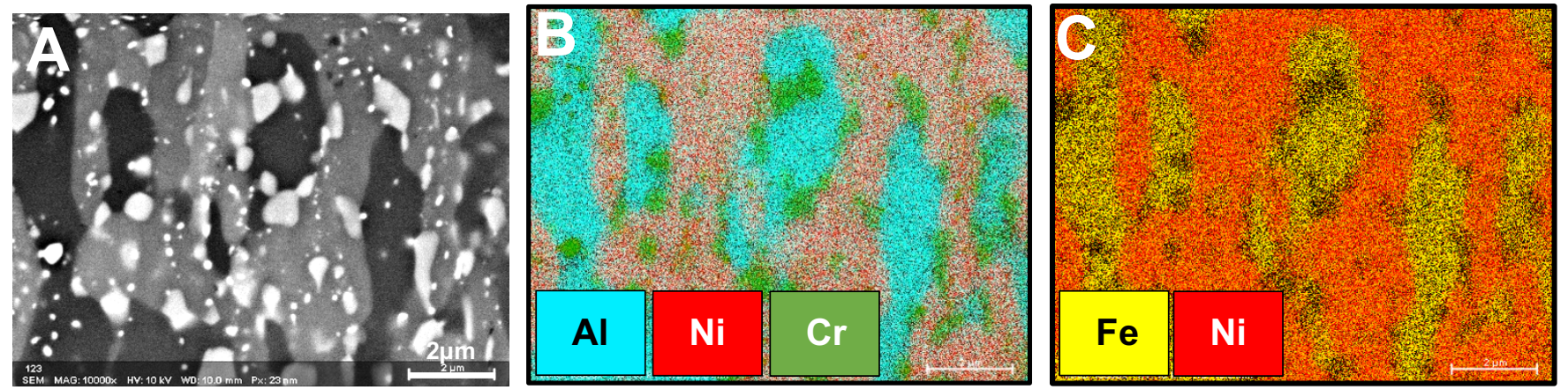

Figure 2. SEM BSE micrograph of columnar region (A) and associated EDS elemental maps for $\mathrm{Al}, \mathrm{Ni}$, $\mathrm{Cr}$, and $\mathrm{Fe}(\mathrm{B} \& \mathrm{C})$ 